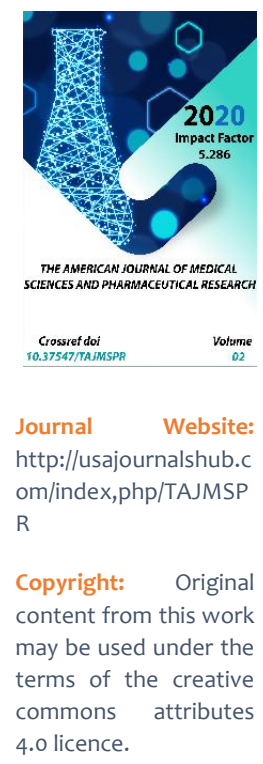

\title{
Features Of Flow Of Diseases Of The Oral Cavity In Workers Of Production Of Fiberglass Structures
}

Jasur Rizaev Alimzhanovich

M. D., Professor, Rector Of The Samarkand State Medical Institute, Uzbekistan

Nazarova Nodira Sharipovna

PhD, Associate Professor, Docenter Of The Department Of Dentistry Of The Samarkand State Medical Institute, Uzbekistan

Berdiev Timur Kaxorovich

Assistent Of The Department Of Dentistry Of The Samarkand State Medical Institute, Samarkand, Uzbekistan

\section{ABSTRACT}

With the progressive growth of the chemical industry and extensive chemization of multiple areas of the national economy, as well as the regular introduction into production of various chemical compounds that have irritating, toxic, sensitizing, carcinogenic properties on the body, it is becoming more relevant and very important to study them in more detail.

\section{KEYWORDS}

Fiberglass structures, chemical compounds, paradont, oral mucosa, styrene.

\section{INTRODUCTION}

Chemical compounds as toxic dust can settle in the form of plaque in the area of the necks of the teeth, or through the damaged mucous membrane for faster penetration and absorption, which causes serious consequences in the form of erosion and necrosis of enamel, periodontitis, stomatitis.
The harm caused by chemicals to certain organs depends on the amount (dose) of these chemicals absorbed by the body. The constant influence of chemical compounds in low concentrations in the air and on the oral mucosa can contribute to changes in the composition of saliva, the structure of 
microbiocenosis, which ultimately leads to a secondary deterioration of the hygienic state of the oral cavity $[2,5]$.

\section{THE PURPOSE OF THE STUDY}

To Study the features of dental diseases in employees of the production of fiberglass structures.

\section{MATERIAL AND METHODS OF RESEARCH}

It is planned to conduct a study of 385 workers. Of these, 125 workers in the production of office furniture made of fiberglass, 96 in production of glass, 164 working for the production of plastic frames.

The data that was received was subjected to statistical processing using the Microsoft Excel application package. The reliability of the difference in parameters was determined by the student's criterion.

\section{RESULTS AND DISCUSSION}

The impact of adverse factors of biological, chemical and physical nature leads to changes in the functioning of various systems of the human body $[9,2,3]$. A large number of studies have shown that the variety and originality of etiological factors of the production environment, their various combinations and ways of influencing the body indicate the features of the development and course of professional pathology, determine the originality of their pathophysiological and pathomorphological essence.

Among employees of industrial enterprises, there is a great need for sanitation of the oral cavity, treatment of periodontal diseases and dental prosthetics. Modern methods of systemic and local prevention of caries and periodontal diseases are almost not implemented among the working population, including those who are exposed to occupational risk factors for dental diseases.

At the same time, against the background of the development of some industries, it is necessary to intensify work to preserve the dental health of employees of individual enterprises.

This problem should be solved by conducting large-scale epidemiological studies at industrial enterprises, followed by a situational analysis of dental morbidity and an assessment of the level of dental care for employees. For a number of enterprises and industries, it is necessary to develop targeted treatment and prevention programs to improve dental care for working contingents, primarily in harmful working conditions. Special attention should be paid to long-term employees who have been exposed to various harmful production factors or their combined effects for a long time.

The high prevalence, tendency to progression, and multi-sided impact on both the dental system and the body as a whole, as well as ambiguous approaches to treatment, make dental diseases one of the most problematic nosologies in modern medicine $[1,4]$.

Fiberglass is currently used in various sectors of the national economy, including shipbuilding, chemical, automobile, road, construction, aviation, production of various types of furniture, agriculture, and domestic use $[3,7]$.

Numerous studies of the dependence of the population's health status on the influence of a chemical factor, conducted in our country and abroad, convincingly show that environmental pollution leads to the development of adverse health effects, which are expressed in an increase in mortality, 
morbidity, deterioration of physical development, and the prevalence of premorbid conditions $[8,5]$. The production processes of forming and collecting fiberglass hull structures are characterized by a high level of professional risk. This risk is determined by a high content of toxic substances in the mixture of NPS, namely, ammonia, styrene, toluene, epichlorhydrin, acetone, hexane, ethanol, formaldehyde, carbon monoxide and dust in the air of working zone area of the molding, certain conventional methods, heating and cooling microclimate, broadband noise, local vibration, forced position of the body while performing work operations.

Thus, the majority of working workers in the fiberglass industry were men aged 40 to 50 years and older $(56.8 \%)$ with more than 15 years of work experience (54.8\%). The workers employed in the new production are also men, but the majority of them were 20-29 years old (73.9\%). About $95 \%$ of the surveyed modern production had 6 years of work experience in the studied production and had not previously worked in harmful working conditions.

When studying the toxic effect of styrene, the degree of information content of integral and specific indicators was evaluated - state of NADP-H-dependent biochemical system involved in the metabolism of foreign compounds, as well as the change of parameters pupillary reactions the parameters of acute toxicity of styrene conducted roundthe-clock for 1 month, experiments with inhalation rat styrene in which were recorded the changes in several physiological parameters and some biochemical systems, the nature of specific changes in parameters of the pupillary reactions in acute and chronic intoxication with styrene.
Assessment of the state of NADP-Hdependent biochemical systems and parameters of pupillary reactions are proposed as a criterion for the toxic effect of styrene.

During the hygienic assessment of the working conditions of moulders and ship collectors of fiberglass hull structures, modern methods of assessing the production environment were used. it was Found that the leading factor is chemical.

For the first time, using modern principles and criteria, occupational risk calculations were performed for the above-mentioned specialists, and the relative risk of occupational diseases among fiberglass production workers was estimated.

The main reasons for the development of chronic occupational diseases (intoxication aromatic hydrocarbons, toxic hepatitis) and formation of risk groups for development of occupational diseases and increasing production of conditionality of development of dyskinetic disorders of the hepatobiliary system and disorders of the autonomic nervous system.

Employees of this production have chronic diseases represented by the following diseases: diseases of the digestive system (54.1\%), diseases of the circulatory system (35.8\%), nervous system ( $26.0 \%)$, endocrine system, eating disorders and metabolic disorders (23.4\%), diseases of the musculoskeletal system and connective tissue (20.9\%). It should be noted that diseases of the digestive system in workers with work experience of more than 15 years $(41.2 \%)$ were diagnosed 3.5 times more often than in lowtrained workers (11.6\%). 
In the structure of diseases of the digestive system, the leading place was occupied by chronic gastritis ( $21.8 \%$ ), followed by peptic ulcer of the stomach and duodenum (12.6\%). Biliary dyskinesia had the highest frequency of diseases of the biliary system $(14.8 \%)$. $(4,9)$.

\section{CONCLUSIONS}

The study of the pathogenetic conditionality of major dental diseases under the action of various industrial hazards is one of the priority areas in dentistry and allows us to develop an effective program for the prevention of major dental diseases.

At the same time, a high prevalence of dental diseases has been noted among working fiberglass structures, which has recently remained unexplored.

Analyzing the literature data on the impact of occupational factors of various chemical industries on the formation of dental pathology, it can be stated that the prevalence of diseases of the hard tissues of the teeth, periodontal tissues and oral mucosa in workers of these industries was significantly more common than in the control groups, where the influence of chemicals on the oral organs is absent.

Among periodontal diseases, gingivitis was found mainly in people with less than 10 years of experience, and periodontitis - in workers with more than 10 years of experience. As the length of service increased, the number of workers with moderate periodontitis increased. The most common disease of the oral mucosa was keratosis, which was observed in workers 6-10 times more often than in the control groups. At the same time, all authors, without exception, pointed to the existence of a link between dental lesions, working conditions and work experience, which confirmed the professional nature of this pathology $[6,9,11]$.

Literature data contain a large amount of data on the impact of various industrial hazards on various body systems, including the state of the oral cavity. However, there is no assessment of the impact of production factors of chemical etiology combined with adverse physical factors of the production environment on the state of hard tissues of the teeth, periodontal and oral mucosa (7.10).

In the available literature, there is no data on the effect of a complex of harmful substances produced by fiberglass on the state of the oral cavity, the relationship of these complexes on the state of the oral fluid of workers is not determined; the influence of dental morbidity of fiberglass workers on the quality of life is not studied.

\section{REFERENCES}

1. Apraksina, E. Yu. Dental morbidity of employees of enterprises associated with vibration / E. Yu. Apraksina, P. I. Pushilin // Medicine and education in Siberia. - 2015. No. 1. - P. 26.

2. Bulkina, N. V. Quality of life as a criterion for choosing a treatment method for included dental defects in patients with generalized periodontitis / N. V. Bulkina, E. V. Turusova, A. Yu. Perunov / / Fundamental research. - 2012. - no. 7-1. - P. 50-53.

3. Influence of caries on the quality of life of patients / O. V. fedotkina, I. M. Shishkina, E. A. Dmitrieva [et al.] / / Endodontics today. - 2014. - no. 1. - Pp. 25-29. Fedotkina, O. V. Quality of life and behavioral risk factors in patients with caries and its complications / O. V. fedotkina / / dental review. Education, 
science and practice in dentistry on a single topic " Ways to improve quality.

4. Galiullina, E. F. Influence of harmful factors in the rubber industry on the periodontological status of workers / E. F. Galiullina, S. V. Averyanov // Periodontics. 2016. - Vol. 21, No. 4 (81). - P. 47-51.

5. Zakirova, Z. A. Increase of explosion and fire safety of production of technical terephthalic acid (TFC) / Z. A. Zakirova, Yu.R. Abdrakhimov // oil and Gas business. - 2012. - No. 6. - P. 502-514.

6. Kabirova, M. F. State of the oral mucosa in workers exposed to technogenic effects / M. F. Kabirova, I. N. Usmanova, A. R. Yapparova / / Health, demography, ecology of Finno-Ugric peoples. - 2015. no. 3. - Pp. 39-40

7. Kalmatov, R. K. Analysis of data on the state of internal ecology of the mucous membranes of the upper respiratory tract when exposed to toxic substances / R. K. Kalmatov // Scientific research: from theory to practice. - 2015. - Vol. 1, No. 4 (5). - P. 90-95.

8. Nazarova N. Sh., Zhumatov U. Zh., Kasimov M. M. the State of local immunological reactivity of the oral cavity in workers in the tobacco industry // Journal of theoretical and clinical medicine, Tashkent - 2014. - no. 4. - Pp. 1719. (14.00.00; no. 3).

9. Nazarova N. Sh., Zhumatov U. Zh. Characteristics of functional conditions of taste analyses of tobacco cultivation employees. European Science. Review. Scientific jurnal. Austria, Vienna. 2015. - No. 7-8. - P. 41-43. (14.00.00; No. 19).

10. Nazarova N. Sh., Zhumatov U. Zh. Effectiveness of physiotherapy procedures in periodontitis in tobacco growers / / Journal of biology and medicine, Samarkand - 2014. - № 4 (80). P. 79.

11. Tooth loss, prosthetic status and treatment needs among industrial workers in Belgaum, Karnataka, India / V.V. Patil, K. Shigli, M. Hebbal, N. Agrawal // J. Oral Sci. - 2012. - Vol. 54, № 4. - P. 285-92.

12. Validation of a Romanian version of the short form of the oral health impact profile (OHIP-14) for use in an urban adult population / O. Slusanschi, R. Moraru, L. Garneata [et al.] // Oral Health Prev. Dent. - 2013. - Vol. 11, № 3. - P. 235-42. 